\title{
Treatment of bile duct stones endoscopically and by extracorporeal shock waves
}

\author{
Oscar L. Koller, Richard W. Norman, Geoffrey K. Turnbull. Michael Woolnough
}

\begin{abstract}
Endoscopic sphincterotomy was performed in a 68-year-old female patient with multiple stones in the common bile duct and cholangitis. Because the extraction of all the stones was not achieved extracorporeal lithotripsy was performed. Following fragmentation all the residual stones passed spontaneously and no complication occurred. Can J Gastroenterol 1988;2(2):49-52
\end{abstract}

Key Words: Bile duct stone, Endoscopic sphincterotomy, Extracorporeal shock wave lithotripsy

R ETAINED BILIARY STONES ARE DIScovered following cholecystectomy in at least 3 to $5 \%$ of patients (1). When endoscopic sphincterotomy was first introduced 15 years ago, it was primarily used for removal of these retained common bile duct stones in high risk individuals. Since then endoscopic sphincterotomy has become widely used in an increasing number of biliary and pancreatic disorders $(2,3)$.

Although endoscopic sphincterotomy with stone removal has been successful in the majority ( 80 to $95 \%$ ) of attempts, there are certain situations which can in- crease the failure rate and decrease the safety of the procedure. Stone(s) larger than $2.0 \mathrm{~cm}$, stones trapped in proximal (intrahepatic) ducts and long stricture of the distal common bile duct pose particular problems (2). Occasionally, blood, purulent bile or debris can obscure vision causing difficulties.

\section{CASE PRESENTATION}

A 68-year-old woman was admitted with an eight day history of dull, aching, abdominal pain radiating into the back. The day prior to admission, she had become more nauseated, noted a temper-

Division of Gastroenterology, Departments of Medicine, Urology and Radiology,

Dalhousie University, Halifax, Nova Scotia

Correspondence and reprints: Dr Oscar Koller, Camp Hill Hospital, Halifax. Nova Scotia B3H 3G2. Telephone (902) 420-2685

Received for publication February 18, 1988. Accepted May 2, 1988

ature rise to $37.8^{\circ} \mathrm{C}$ and her urine had turned a dark colour. She had had brief episodes of sharp, right upper quadrant abdominal pain lasting approximately 5 mins for approximately 15 years. A cholecystectomy had been performed in 1960 but a common bile duct exploration was not done at that time. Because of the attacks of sharp right upper quadrant abdominal pain, a common bile duct exploration was performed in 1974 and an undisclosed number of bile duct stones were removed. Otherwise, prior to admission, there had been no change in bowel habit and no pain other than that in the epigastrium and right upper quadrant. Stool colour was normal. The abdominal pain was only eased with narcotic analgesics.

In addition to the previously noted operations, the patient had had a right modified mastectomy performed in 1986. Just prior to this, a diagnosis of hypertension had been made. Medications on admission were tamoxifen $10 \mathrm{mg}$ bid, Aspirin $325 \mathrm{mg}$ every two days and indapamide $2.5 \mathrm{mg}$ every two days. She was a smoker of three-quarters of a pack per day for the previous 50 years and drank infrequently. Family history was significant 


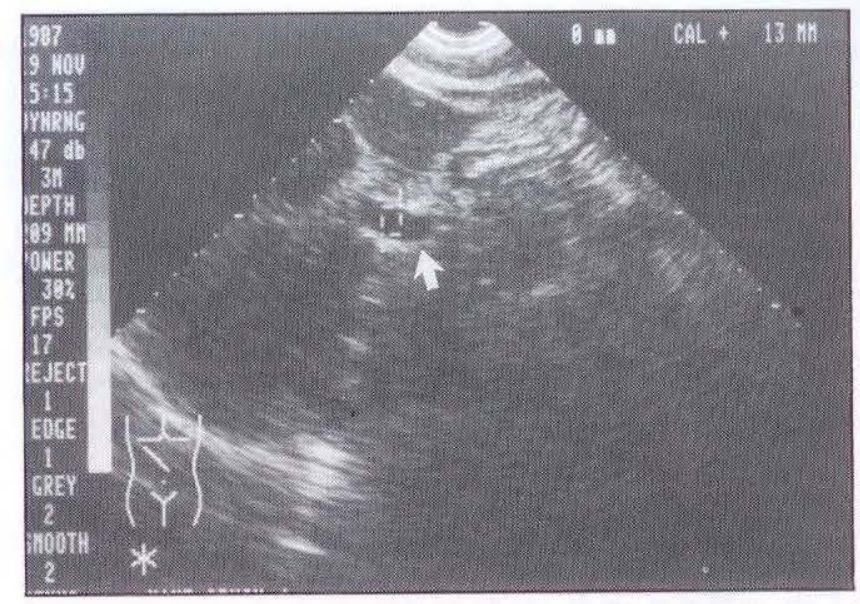

Figure 1) Pre-operative ultrasound study showing dilatation ( $13 \mathrm{~mm}$ ) of the common hepatic duct (arrowed)

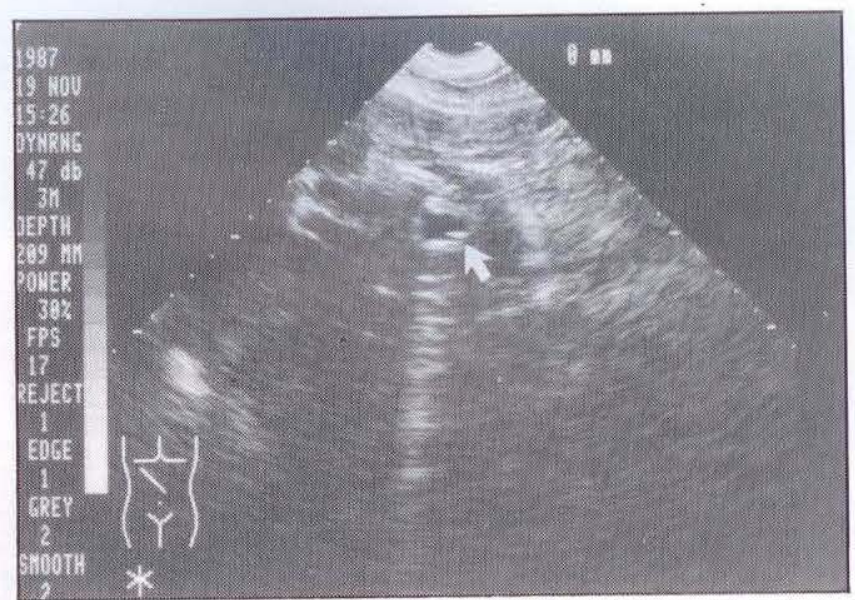

Figure 2) Pre-operative ultrasound study showing calculi in the common bile duct (arrowed) in that her daughter had had her gallbladder removed when she was in her 20 s. She had one sister who had had cancer of the throat and her mother had died of cancer of the uterus.

On physical examination the patient was not in acute distress with stable vital signs, pulse $90 / \mathrm{min}$, blood pressure of $130 / 90 \mathrm{mmHg}$, temperature of $36.6^{\circ} \mathrm{C}$. No jaundice, finger clubbing or skin lesions were noted. Chest exam identified a previous right mastectomy, and bilateral basal inspiratory crackles on auscultation, more pronounced on the left side. On cardiovascular examination, jugular venous pressure and peripheral pulses were normal as was auscultation of the heart. On abdominal examination, there was no tenderness to palpation. The liver edge was felt to be of normal consistency with a span of $10 \mathrm{~cm}$. There was no palpable spleen or other palpable masses. Rectal examination was normal. No other abnormalities were detected.

At the time of admission, white blood cell count was elevated at $17,200 / \mathrm{mm}^{3}$ with a hemoglobin of $12.9 \mathrm{~g} / 100 \mathrm{~mL}$ and increased platelets of $616,000 / \mathrm{mm}^{3}$ with an elevated erythrocyte sedimentation rate of $45 \mathrm{~mm} / \mathrm{L}$. Amylase was normal at $36 \mathrm{iu} / \mathrm{L}$ with a normal total bilirubin of $17 \mu \mathrm{mol} / \mathrm{L}$, alkaline phosphatase was $124 \mathrm{iu} / \mathrm{L}$, (normal, 30 to 115 ), aspartate aminotransferase $87 \mathrm{iu} / \mathrm{L}$, (normal, 7 to 50) and gamma glutamyltransferase 143 iu/L (normal, less than 40). Prothrombin time and partial thromboplastin time were normal. An abdominal ultrasound was performed the day of admission showing a dilated common bile duct but normal intrahepatic ducts (Figure 1). At least two stones were seen in the common bile duct on ultrasound (Figure 2).

The following day endoscopic retrograde cholangiography (Figure 3) was performed and endoscopic sphincterotomy was carried out. One stone was removed by basket extraction. A large amount of pus drained from the common bile duct, therefore, no further manipulation was carried out and a nasobiliary catheter was inserted. The patient was monitored over the weekend while on broad spectrum antibiotic coverage and a cholangiogram was performed three days later. At this time, three common bile duct stones remained (Figure 4). On the following day, extracorporeal shock wave lithotripsy (ESWL) was carried out using an unmodified HM-3 Dornier lithotripter with 2325 shocks at $21 \mathrm{kV}$. The stones were fragmented and a follow-up cholangiogram the following day showed complete removal of the stones (Figure 5).

Recovery was uneventful; the day after the lithotripsy, alkaline phosphatase had dropped to $73 \mathrm{iu} / \mathrm{L}$, aspartate aminotransferase had risen to $166 \mathrm{iu} / \mathrm{L}$ and the total bilirubin was essentially unchanged at $15 \mu \mathrm{mol} / \mathrm{L}$. At discharge, complete blood count identified a white blood count of 9700 with a mild anemia of $10.5 \mathrm{~g} / 100 \mathrm{~mL}$.

\section{DISCUSSION}

Following endoscopic sphincterotomy, common bile duct stones can pass spontaneously, or more commonly, their pas-

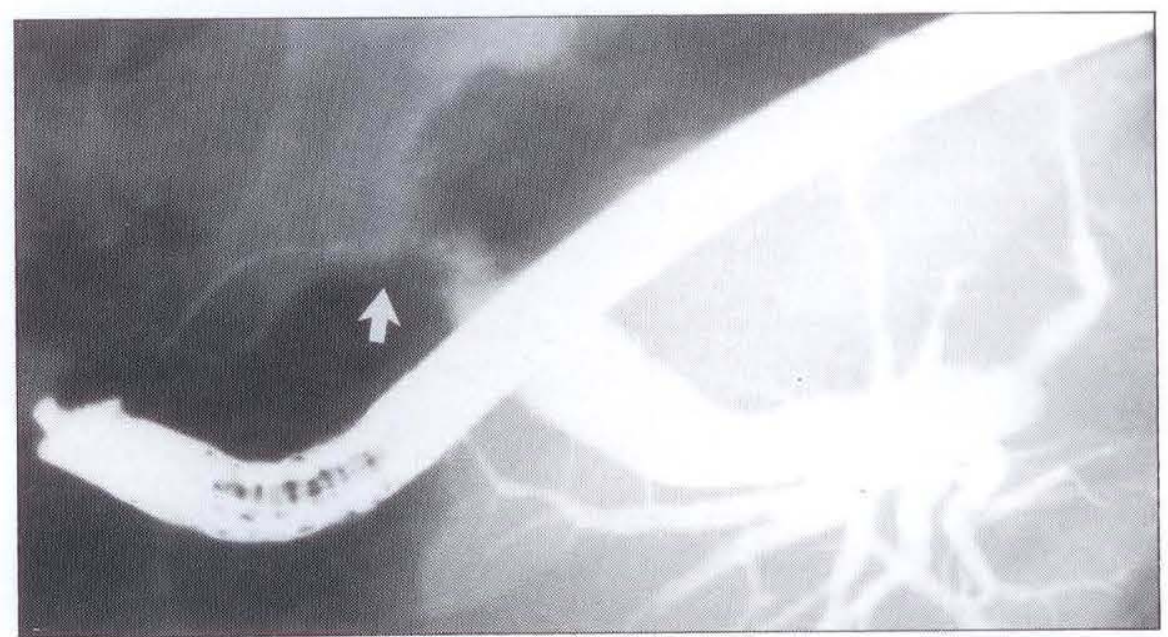

Figure 3) Initial endoscopic retrograde cholangiopancreatography showing several calculi in the proximal and distal common duct (arrowed) 


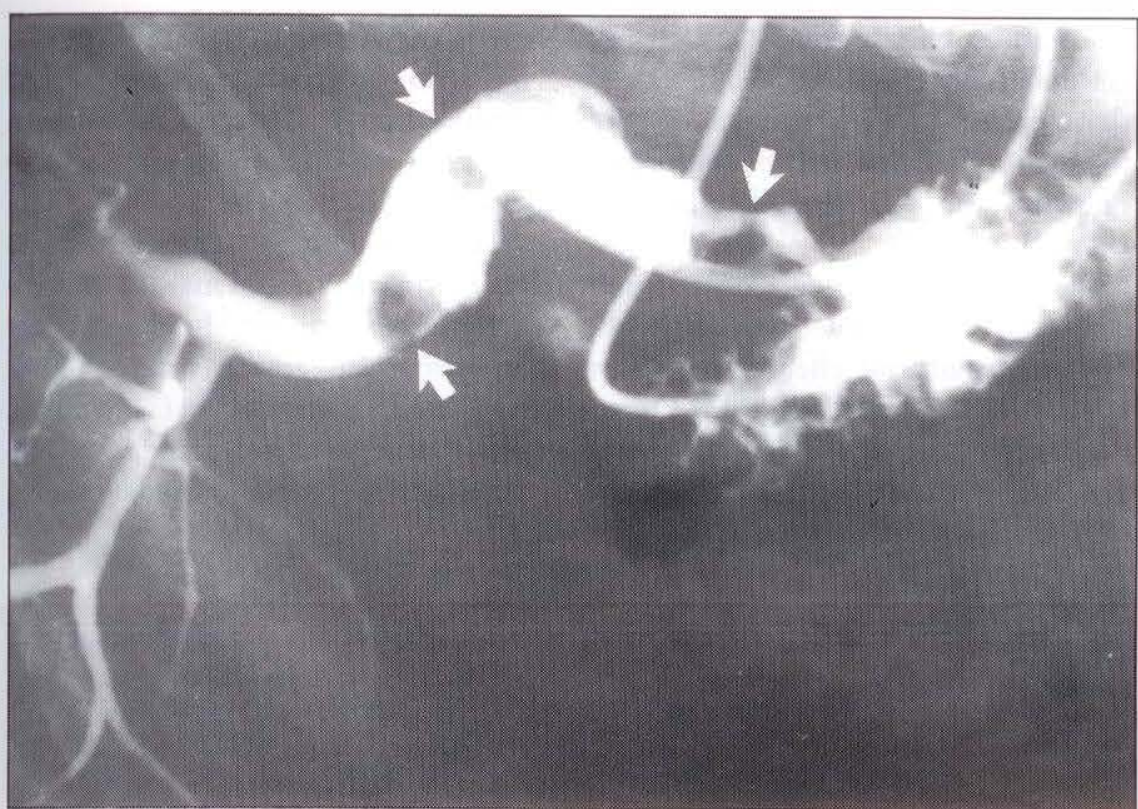

Figure 4) Pre-ESWL, post sphincterotomy and basket extraction, showing retained biliary calculi on injection of nasobiliary catheter

sage is facilitated by basket or balloon extraction. If the stone(s) cannot be removed because of their size or other difficulties, fragmentation or dissolution is necessary.

Different methods for stone fragmentation have been implemented, using pure mechanical, electrohydraulic, ultrasonic or laser energy sources (1-3). Many of these methods are experimental at present and their effectiveness has to be further evaluated. When dissolution is the aim, nasobiliary drains allow infusion of different chemicals directly into the common bile duct. Percutaneous and transhepatic drains can be inserted directly into the gallbladder. Use of monoctanoin and methyl-tert-butyl ether has been tried with variable success (3).

Biliary lithotripsy was inspired by the success of fragmentation of kidney stones by extracorporeally generated shock waves. The method was pioneered in Munich, West Germany (4), but has rapidly gained popularity in North America $(5,6)$. Shock waves can be generated by different methods; electrostatic spark discharge, electromagnetic shock and pulsed piezoelectric shock $(7,8)$. Large immersion water tanks have been replaced in newer, second generation models with elastic and compressible water bags, improving the convenience of the procedure (7). Biliary lithotripsy includes treatments for both gallbladder and com- mon bile duct stones.

The shock wave treatment of gallbladder stones requires ultrasound targeting (9). Patients selected for ESWL should have a history of biliary colic (symptomatic gallstone disease) and a functioning gallbladder, as documented by visualization on oral cholecystography (9). The disintegration of stones will produce numerous small fragments. There is some degree of uncertainty whether these fragments will pass without difficulty. At least theoretically they could induce

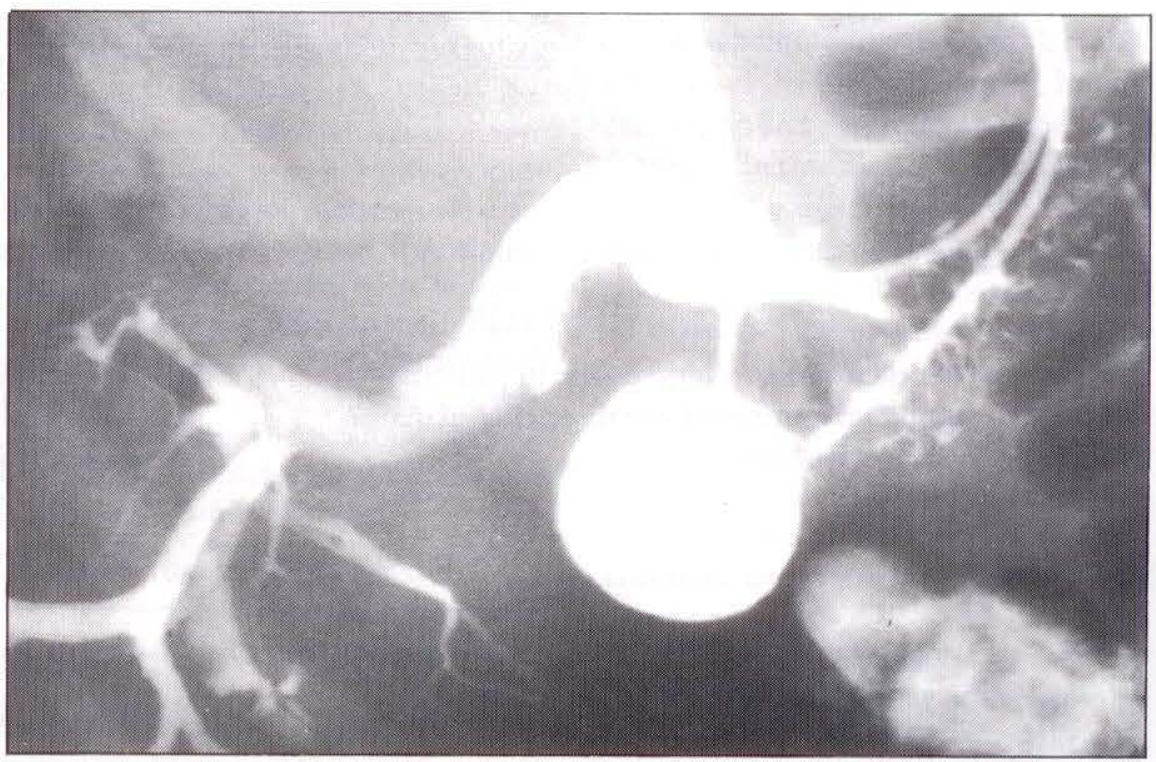

Figure 5) Post-ESWL injection via nasobiliary catheter showing complete clearance of the common duct calculi velopment of the method, all patients complications: biliary colic, cholecystitis, cholangitis or pancreatitis (7). Therefore, successful therapy of gallbladder calculi likely requires a combination of mechanical fragmentation plus chemical dissolution (8,9). Because of the possibility of stone reformation, many of the patients will also require maintenance therapy with a solvent. An endoscopic sphincterotomy is not routinely required.

Common bile duct stones need direct, fluoroscopic targeting and can be treated on a conventional kidney device $(7,9)$. Visualization is best achieved through a previously inserted nasobiliary catheter (10). Logical candidates are patients in whom a previous endoscopical effort with endoscopic sphincterotomy failed to remove common bile duct stones, and have a nasobiliary catheter in place $(7,9,10)$.

The ideal ESWL apparatus will treat both renal and biliary stones, providing both sonographic and $\mathrm{x}$-ray imaging for targeting (11). In the early phase of dewere treated under general anesthesia. Presently, however, the majority of procedures is performed under intravenous analgesia (12).

It is estimated that by the end of 1987 at least 300 patients received ESWL for biliary stones. An increasing number of publications report on successfully treated cases or small groups of patients $(4,6,8,10,12)$. The largest experience is 
the one of the Munich group, with an excellent success rate (9). Stones could be fragmented in all but one of about 150 patients treated for gallbladder stones. Complete disappearance of the fragments might occur within days, but after six months $80 \%$ of patients with previous solitary stones showed no evidence of residuum (9). Results with multiple stones have not been as favourable, multiple treatment sessions are sometimes necessary.

\section{REFERENCES}

1. Tompkins RK, Doty JE. Modern management of biliary tract stone disease. Adv Surg 1987;20:279-302.

2. Kozarek RA. Endoscopic therapy of biliary tract stones. Advances in hepatobiliary diseases seen in practice. Postgr Course, AASLD, Chicago, Oct 25-26, 1987.

3. Haskin PH, Teplick SK. Nonoperative methods of common duct stone management. Sem Ultrasound CT MR 1987:8:134-54

4. Sauerbruch T, Delius M, Paumgartner G, et al. Fragmentation of gallstones by extracorporeal shock waves. N Engl J Med 1986;314:818-22

5. Becker CD, Fache JS, Gibney RG,
Common bile duct stone lithotripsy is similarly successful. In about $80 \%$ of these patients, ESWL resulted in stone fragments which passed spontaneously or could easily be extracted endoscopically (9).

The available experience demonstrated that ESWL is tolerated very well without serious adverse effects by the vast majority of patients $(5,6,8-10,12)$. Organ (lung, pancreas, kidney and others) damage can be avoided with careful tech- nique and targeting (9). Laboratory tests reveal no significant sign of hepatobiliary dysfunction (9). Cholecystitis and pancreatitis are a concern, but rare complications,

Further worldwide experience will answer important questions regarding the recurrence of stones, duration of post lithotripsy drug treatment, cost-benefit data and long term safety (7). With the predictable technical progress, indications for ESWL can be broadened.
Scudamore $\mathrm{CH}$, Burhenne $\mathrm{HJ}$.

Choledocholithiasis: Treatment with extracorporeal shock wave lithotripsy. Radiology 1987;165:407-8.

6. Becker CD, Nagy AG, Fache JS, Gibney RG, Burhenne HJ. Obstructive jaundice and cholangitis due to choledocholithiasis. Treatment by extracorporeal shock wave lithotripsy. Can J Surg 1987;30:418-9.

7. Ferrucci JT. Biliary lithotripsy. What will the issues be? Am J Radiol 1987:149:227-31.

8. Ell C, Kerzel W, Heyder N, Becker V. Hermanek P, Domschke W. Piezoelectric lithotripsy of gallstones. Lancet 1987;ii:1149-50.

9. Paumgartner G. Extracorporeal shock-wave lithotripsy of gallstones. Advances in hepatobiliary diseases seen in practice. Postgr Course AASLD, Chicago, October 25-26, 1987.

10. Sauerbruch T, Holl J, Sackmann M, et al. Treatment of bile duct stones by extracorporeal shock. Sem Ultrasound CT MR 1987:8:155-61.

11. Burhenne HJ. The promise of extracorporeal shock wave lithotripsy for the treatment of gallstones. Am J Radiol 1987;149:233-5.

12. Sackmann M, Weber W, Delius M, et al. Extracorporeal shock wave lithotripsy of gallstones without general anesthesia: First clinical experience. Ann Intern Med 1987;107:347-8.

\section{Clinical Quiz}

Please note, there may be more answers than asked for in the question.

\section{NUTRITION}

\section{List four major clinical manifestations of vitamin A} toxicity.

2. Acute zinc deficiency has been described in patients receiving parenteral nutrition. Give three clinical manifestations of zinc deficiency.

(Answers page 78)

\section{COLON}

1. What are the causes, clinical manifestations and treatment of solitary rectal ulcer?

2. What four clinical features would make you suspect that a patient was suffering from cathartic colon (Answers page 78) 


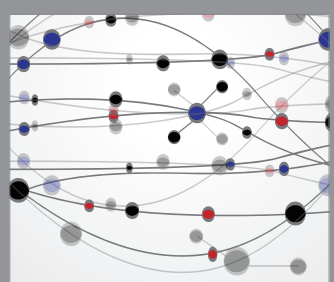

The Scientific World Journal
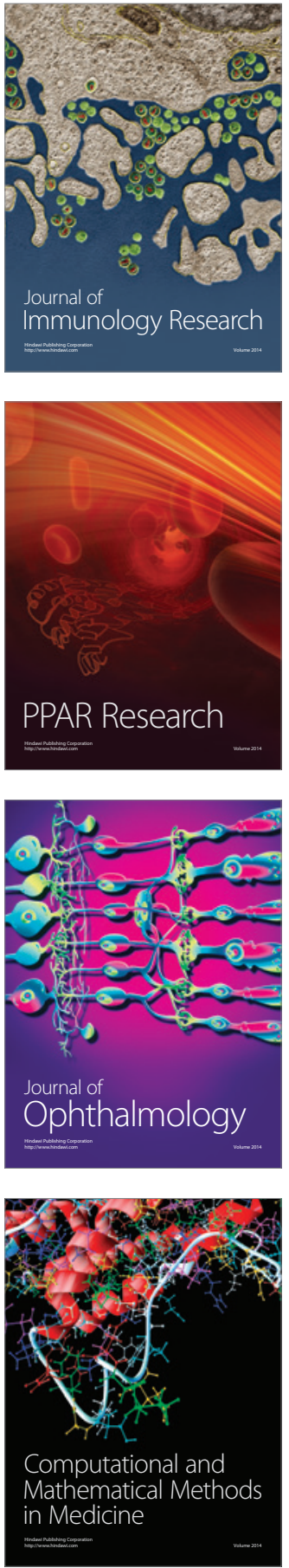

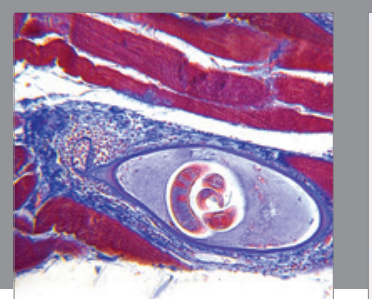

Gastroenterology Research and Practice

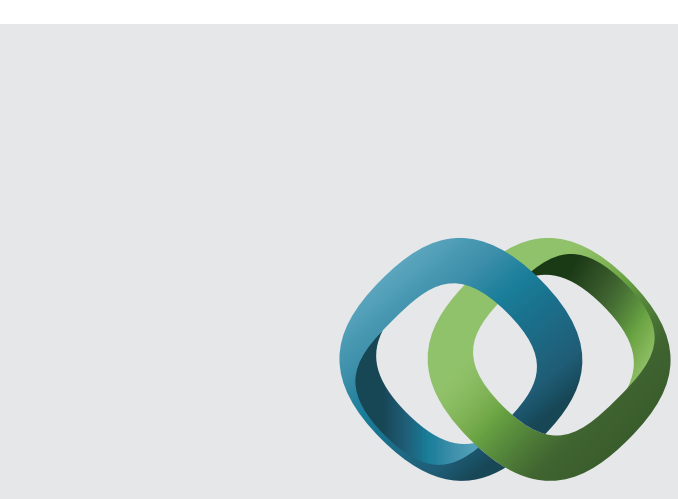

\section{Hindawi}

Submit your manuscripts at

http://www.hindawi.com
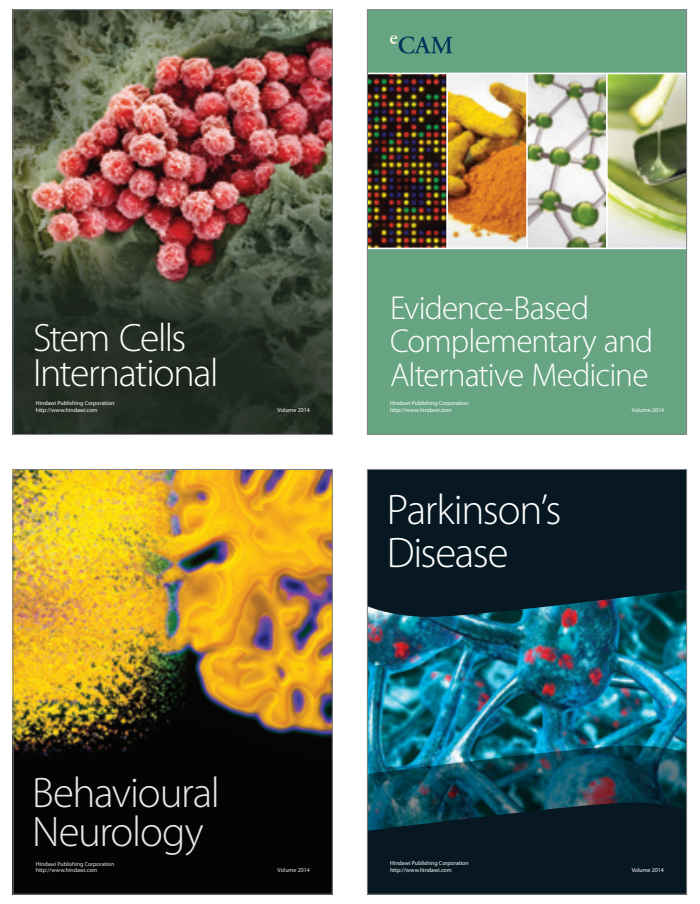
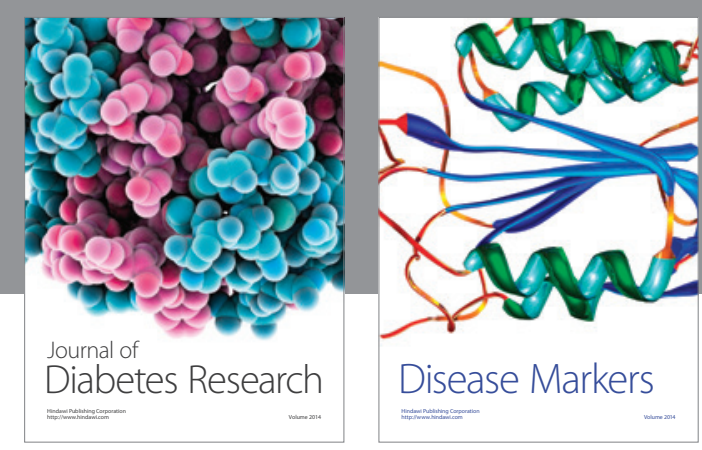

Disease Markers
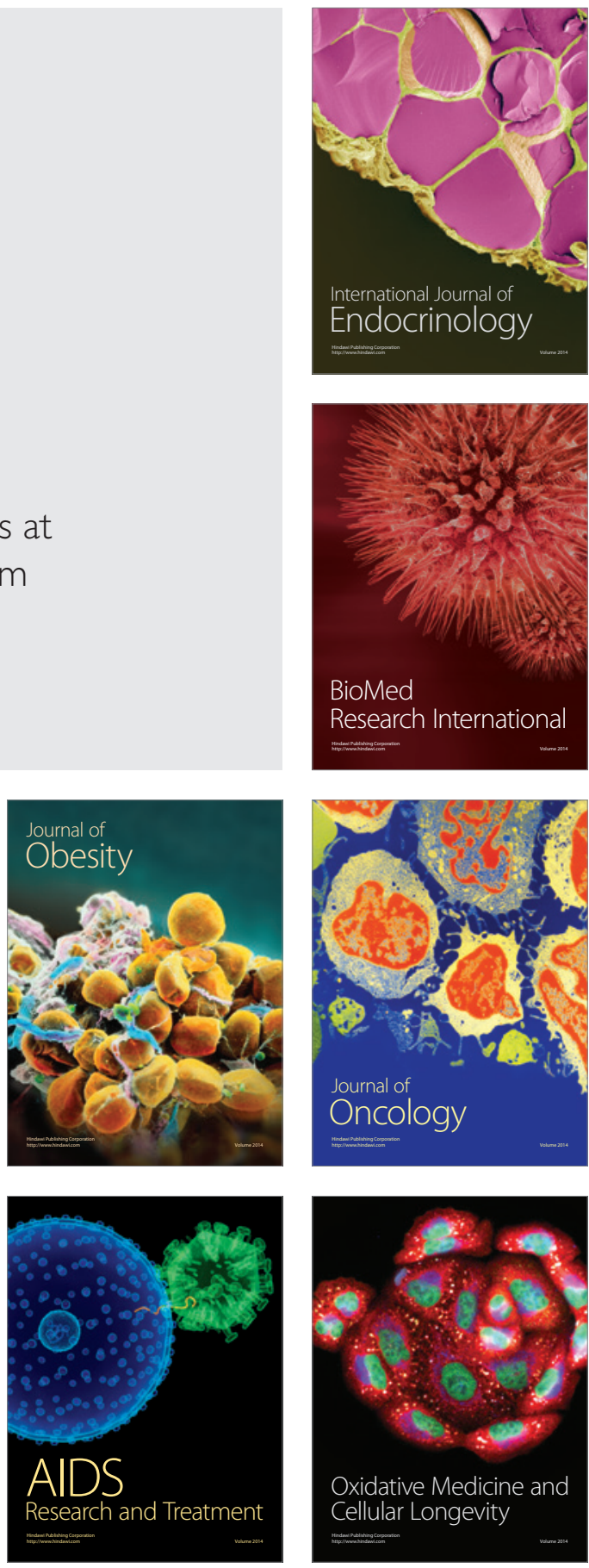